\title{
Development of myopia as a hazard for workers in pneumatic caissons
}

\author{
A Onoo, M Kiyosawa, H Takase, Y Mano
}

Br J Ophthalmol 2002;86:1274-1277

See end of article for authors' affiliations

.....................

Correspondence to: Motohiro Kiyosawa, MD Department of

Ophthalmology and Visual Science, Postgraduate School of Medicine, Tokyo Medical and Denta University, Yushima 1-chome 5-45, Bunkyo-ku, Tokyo, $113-8519$ Japan; m.kiyosawa.oph@tmd.ac.jp

Accepted for publication 29 May 2002

\begin{abstract}
Background/aim: Pneumatic caisson engineering has been developed for large civil engineering constructions. Because of complaints of blurred vision by personnel working in pneumatic caissons, the development of myopia was suspected. The aim of this study was to determine the cause of the blurred vision and the mechanism underlying the changes.

Methods: 12 caisson workers underwent a complete ophthalmological examination after completing up to 11 weeks of work (4 days/week) in a pneumatic caisson. Six months later, nine of the workers were examined again.

Results: Nine subjects were myopic at the initial examination, and seven of these were considered to have developed the myopia after starting to work in the pneumatic caisson. Six months after completion of the work, the mean refractive change was significantly towards hyperopia.

Conclusions: The blurred vision in pneumatic caisson workers was in all likelihood due to the development of myopia. The refractive shift towards hyperopia after completion of work in the pneumatic caisson supports this and demonstrates that the changes were temporary. The myopia is similar to the myopia seen in patients treated by hyperbaric oxygen. Careful monitoring of the refraction of caisson workers should be performed for industrial health control.
\end{abstract}

$\mathrm{T}$ he recent escalation in the scale of civil engineering has increased the necessity of working at great depths, and pneumatic caisson engineering has been developed for this purpose. In addition to overcoming the great pressures, supplying the correct mixture of helium, nitrogen, and oxygen to prevent decompression sickness and oxygen poisoning has been developed.

Hyperbaric traumas, such as pressure effects, air embolisms, decompression sickness, and aseptic necrosis of the femoral head are known to occur in people working under these conditions. $^{2-4}$ Therefore, several restrictive laws have been enacted by the Japanese government to protect workers engaged in this type of work.

Although the medical conditions of the caisson workers are carefully monitored, ophthalmological complications have not been reported. We report complaints of blurred vision, especially blurred distant vision, in a field survey of workers who were engaged in the construction of a bridge at the Nagoya South Sea Port. To determine the cause of this visual disturbance, comprehensive ophthalmological examinations were performed on 12 workers involved in caisson work at this construction site. These examinations demonstrated that more than half of workers had progressive myopia, and most of them recovered 6 months after leaving this job. We present our findings and discuss the probable cause of this transient myopia and compare it with the myopia and nuclear cataracts induced following hyperbaric oxygen treatment.

\section{MATERIALS AND METHODS}

\section{Subjects}

Twelve workers were examined ophthalmologically on 31 October 1995, after working for up to 11 weeks under high pressure. Nine of them were re-examined 6 months later and were questioned about changes of their ophthalmological symptoms.

The refraction was estimated by five measurements with an autorefractometer (AR-600, Nidek, Gamagori, Japan). Ophthalmological evaluations included slit lamp examination of the cornea, lens and vitreous body, and fundus examination by indirect ophthalmoscopy.

\section{Working environment}

The workers were engaged in building a large bridge tower base over the Nagoya South Sea Port. The work was initiated on 8 August and lasted until 27 October 1995, and the main task of the workers was machine maintenance. Each working period was 29-119 minutes at between 4.15 and 4.75 atmospheres absolute pressure (ATA) in their working records. Work was generally performed 4 days/week for each worker. The total accumulated numbers of workers (men $\times$ sessions) was 524.

This great depth pneumatic caisson engineering method is a newly modified method and is different from the traditional caisson method. In the protocol, workers entered a compression room at sea level which is named the "helium lock" (Fig 1). Air pressure is raised to 3 ATA at the rate of 0.8 or less ATA/ min with natural air. When the air pressure was more than 3 ATA, the workers were requested to wear a gas inhalation mask and start to breathe a tri-mixed gas of $\mathrm{He}, \mathrm{N}_{2}$, and $\mathrm{O}_{2}$, at $38 \%, 32 \%$, and $30 \%$, respectively. The air pressure was continuously raised to 4 or 5 ATA, at a rate of $0.8 \mathrm{ATA} / \mathrm{min}$ or less. Then they proceeded into the working room and engaged in the machine maintenance job at this high pressure. The working time usually lasted for 60 to 120 minutes.

After the work was accomplished, the workers were decompressed to 4 ATA at a rate of less than $0.8 \mathrm{ATA} / \mathrm{min}$ in the trimixed gas. Then, they continued to be decompressed to 2.5 ATA at the rate of $0.1 \mathrm{ATA} / \mathrm{min}$ in natural air. After the pressure was decompressed to 2.5 ATA they were requested to breathe in $\mathrm{O}_{2}$ for 25 minutes, and in fresh air for 5 minutes to accelerate inert gas exhaustion. This completed one cycle of work.

The total exposure of the workers to the oxygen was estimated by the unit of pulmonary oxygen toxicity dose (UPTD). ${ }^{5}$ Although, this unit was established to estimate pulmonary oxygen toxicity, UPTD was also used to determine the total exposure of the subjects to oxygen for this study. UPTD was calculated by the following formula: 
Helium mixed gas system

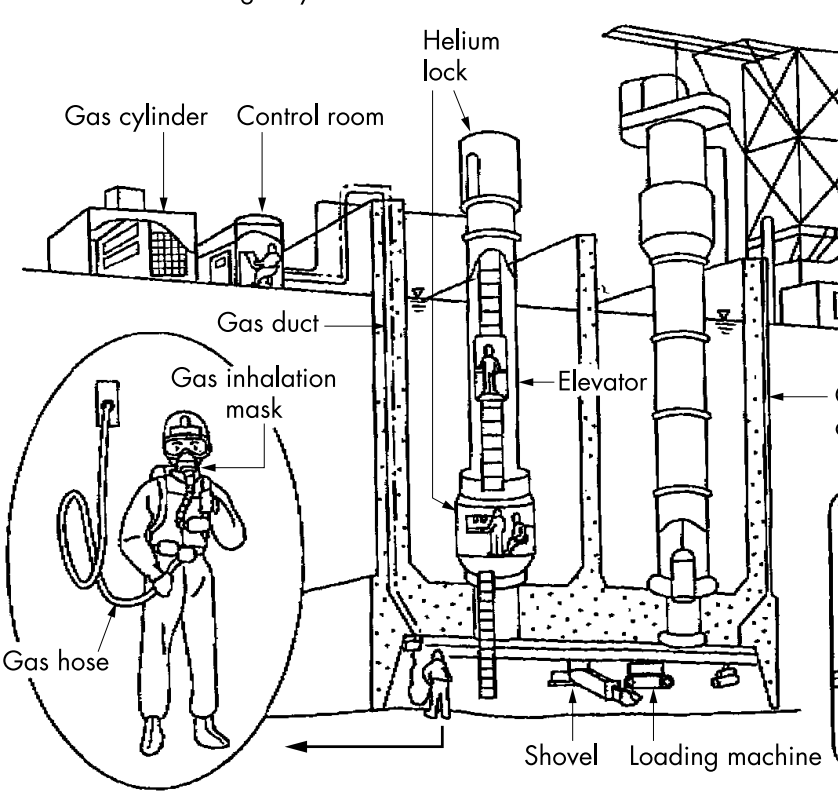

Figure 1 A great depth pneumatic caisson by combination of helium mixed gas system and remote control system. (Adapted and modified from Hukumoto et $\mathrm{al}^{l}$.)
$\mathrm{UPTD}=\mathrm{t}\left(\left(\mathrm{Po}_{2}-0.5\right) / 0.5\right)^{0.83}$

where $t$ represents the exposure time in minutes, $\mathrm{PO}_{2}$ is the partial pressure of oxygen, and a partial pressure of oxygen of 0.5 is the proposed threshold that no one develops pulmonary fibrosis. If one breathes $100 \% \mathrm{O}_{2}$ for 1 minute the toxicity dose is 1 UPTD. The value 0.83 is an approximation constant that was determined to relate UPTD to pulmonary fibrosis.

\section{RESULTS}

The workers' data with total working time and UPTD are shown in Table 1. Their ages ranged between 22 to 57 years with a mean of 40 (SD 11.9) years. Nine of 12 subjects complained of blurred distant vision (cases 1-4, 6-9, and 12), and three of these subjects also complained of pain or itching of the eyes (cases 1, 6, and 7). The interval between the first exposure and first onset of blurred vision was between 9 and 50 days. The total number of sessions until the onset of complaint was 4-30 sessions, and the total working time until the first complaint was 346-2407 minutes.

The nine workers who complained of blurred distant vision had performed 18 or 44 sessions until the first ophthalmological examination. Their total working time was 1269 to 3833 minutes. Total exposure to oxygen of these nine workers was 5628 to 17745 UPTD.

The results of the ophthalmological examination at the completion of the job are shown in Table 2. Nine subjects (cases 1-4, 6-9, and 11) were myopic. We suspected the presence of late onset myopia in seven of these nine myopic subjects (cases 1, 3-6, 8, and 9). For example, the visual acuity of cases 1 and 4 was less than 0.1 in each eye with the same spectacles they had used to pass a driver's vision test 1 year earlier. Five subjects (cases 3, 5, 6, 8, and 9) had passed the vision test for the last renewal of a driving licence without glasses within 3 years, and their visual acuity in the better eye was 0.7 or better without correction. The decrease of uncorrected vision in these subjects with their complaint of blurred vision was suspected to be due to a recent shift to myopia (-).

The shift of the refraction was shown not to be due to an increased accommodative tonus because 20 eyes of the 10 subjects (except four eyes of two subjects) had the myopia even after instillation of cycloplegic eye drops (Mydrin P, 0.5\% tropicamide and $0.5 \%$ phenylephrine hydrochloride). In four eyes of two subjects (cases 10 and 12), cycloplegia induced a $+1.00 \mathrm{D}$ to $+1.87 \mathrm{D}$ shift in the direction of hyperopia $(+)$ suggesting an increase of accommodative tonus.

All subjects but one had clear crystalline lenses and their corrected visual acuity was better than 0.8 . One case had an incipient senile cataract (case 1).

Nine of 12 workers, except cases 1, 2 and 11, had a repeat ophthalmic examination 6 months later (Table 3). At this time, four subjects (cases 3, 4, 5, and 6), had a decrease of myopia or increase of hyperopia of more than $0.5 \mathrm{D}$ (change of refraction

Table 1 Description of caisson workers

\begin{tabular}{|c|c|c|c|c|c|}
\hline $\begin{array}{l}\text { Patient } \\
\text { No }\end{array}$ & Age/sex & Complaints & $\begin{array}{l}\text { Onset of blurred vision from first } \\
\text { exposure }\end{array}$ & $\begin{array}{l}\text { Total period of exposure } \\
\text { in hyperbarics }\end{array}$ & $\begin{array}{l}\text { Unit pulmonary } \\
\text { toxicity dose }\end{array}$ \\
\hline 1 * & $57 / M$ & Blurred distant vision, ocular pain & $1531 \mathrm{~min} / 20$ sessions (43 days) & $3419 \mathrm{~min} / 40$ sessions & 14594 \\
\hline 2 * & $51 / M$ & Blurred distant vision & $1310 \mathrm{~min} / 13$ sessions (14 days) & $2172 \mathrm{~min} / 22$ sessions & 10461 \\
\hline $3 *$ & $50 / M$ & Blurred distant vision & $2407 \mathrm{~min} / 30$ sessions (42 days) & $3075 \mathrm{~min} / 36$ sessions & 17745 \\
\hline $4^{*}$ & $48 / M$ & Blurred distant vision & $1647 \mathrm{~min} / 17$ sessions (25 days) & $2490 \mathrm{~min} / 27$ sessions & 10482 \\
\hline 5 & $48 / M$ & - & - & $2218 \mathrm{~min} / 23$ sessions & 10768 \\
\hline $6 *$ & $45 / M$ & Blurred distant vision, itching & $492 \mathrm{~min} / 6$ sessions ( 37 days) & $2522 \mathrm{~min} / 27$ sessions & 10681 \\
\hline $7 *$ & $42 / M$ & Blurred distant vision, itching & $346 \mathrm{~min} / 4$ sessions (10 days) & $2019 \mathrm{~min} / 21$ sessions & 10646 \\
\hline $8 *$ & $38 / M$ & Blurred distant vision & $538 \mathrm{~min} / 5$ sessions (9 days) & $2703 \mathrm{~min} / 28$ sessions & 11894 \\
\hline $9 *$ & $29 / M$ & Blurred distant vision & Not certain & $3833 \mathrm{~min} / 44$ sessions & 15495 \\
\hline 10 & $25 / M$ & - & - & $851 \mathrm{~min} / 15$ sessions & 4318 \\
\hline 11 & $25 / M$ & - & - & $2284 \mathrm{~min} / 26$ sessions & 9205 \\
\hline $12 *$ & $22 / M$ & Blurred distant vision & $1006 \mathrm{~min} / 12$ sessions (50 days) & $1269 \mathrm{~min} / 18$ sessions & 5628 \\
\hline
\end{tabular}




\begin{tabular}{|c|c|c|c|c|}
\hline $\begin{array}{l}\text { Patient } \\
\text { No }\end{array}$ & Eye & $\mathrm{VA}_{\mathrm{sc}} /\left(\mathrm{VA}_{\mathrm{cc}}\right)$ & Ref*/cycloplegics & Other remarks \\
\hline 1 & $\begin{array}{l}R \\
L\end{array}$ & $\begin{array}{l}0.08 /(0.6) \\
0.06 /(0.8)\end{array}$ & $\begin{array}{l}-2.87 / 0 \dagger \\
-3.87 /+0.12\end{array}$ & Driver's licence with weaker glasses $\ddagger$ \\
\hline 2 & $\begin{array}{l}R \\
L\end{array}$ & $\begin{array}{l}0.2 /(1.2) \\
0.2 /(0.9)\end{array}$ & $\begin{array}{l}-1.37 /+0.25 \dagger \\
-1.37 /+0.25\end{array}$ & Left impending branch retinal vein occlusion \\
\hline 3 & $\begin{array}{l}R \\
L\end{array}$ & $\begin{array}{l}0.5 /(1.2) \\
0.2 /(1.2)\end{array}$ & $\begin{array}{l}-1.25 / 0 \dagger \\
-1.62 /+0.25\end{array}$ & Driver's licence without spectacleł \\
\hline 4 & $\begin{array}{l}R \\
L\end{array}$ & $\begin{array}{l}0.1 /(1.0) \\
0.1 /(1.0)\end{array}$ & $\begin{array}{l}-2.62 /+0.12 \dagger \\
-3.00 / 0\end{array}$ & Driver's licence with weaker glasses $\ddagger$ \\
\hline 5 & $\begin{array}{l}R \\
L\end{array}$ & $\begin{array}{l}0.1 /(1.0) \\
0.9 /(1.0)\end{array}$ & $\begin{array}{l}-0.25 /+0.37 \\
0.50 /+0.25\end{array}$ & Driver's licence without spectacles $\ddagger$ \\
\hline 6 & $\begin{array}{l}R \\
L\end{array}$ & $\begin{array}{l}0.2 /(1.0) \\
0.4 /(1.5)\end{array}$ & $\begin{array}{l}-2.25 / 0 \dagger \\
-1.87 /+0.25\end{array}$ & Driver's licence without spectacles $\ddagger$ \\
\hline 7 & $\begin{array}{l}R \\
L\end{array}$ & $\begin{array}{l}0.8 /(1.0) \\
1.5 /(1.5)\end{array}$ & $\begin{array}{l}-0.62 /+0.25 \dagger \\
0 /+0.13\end{array}$ & \\
\hline 8 & $\begin{array}{l}R \\
L\end{array}$ & $\begin{array}{l}0.2 /(1.0) \\
0.5 /(1.0)\end{array}$ & $\begin{array}{l}-1.37 /+0.12 \dagger \\
-1.75 / 0\end{array}$ & Driver's licence without spectacles $\ddagger$ \\
\hline 9 & $\begin{array}{l}R \\
L\end{array}$ & $\begin{array}{l}0.4 /(1.0) \\
0.5 /(1.2)\end{array}$ & $\begin{array}{l}-1.87 /+0.5 \dagger \\
-1.87 /+0.5\end{array}$ & $\begin{array}{l}\text { Driver's licence without spectacles } \neq \\
\text { Bilateral corneal dystrophy }\end{array}$ \\
\hline 10 & $\begin{array}{l}R \\
L\end{array}$ & $\begin{array}{l}1.2 /(1.2) \\
1.5 /(1.5)\end{array}$ & $\begin{array}{l}-1.00 /+1.25 \\
-1.25 /+1.87\end{array}$ & Left macula cornea \\
\hline 11 & $\begin{array}{l}R \\
L\end{array}$ & $\begin{array}{l}0.08 /(1.5) \\
0.08 /(1.5)\end{array}$ & $\begin{array}{l}-3.75 /+0.37 \\
-4.00 /+0.25\end{array}$ & \\
\hline 12 & $\begin{array}{l}R \\
L\end{array}$ & $\begin{array}{l}1.5 /(1.5) \\
0.2 /(1.5)\end{array}$ & $\begin{array}{l}-1.12 /+1.12 \dagger \\
-0.75 /+1.00\end{array}$ & \\
\hline
\end{tabular}

$>+0.5$ ), and four workers (cases $8,9,10,12$ ) had a refractive change within plus or minus 0.50 D. Only one subject, case 7 , had an increase of myopia. The mean refractive change was significantly toward hyperopia (change of refraction $>0, p$ $<0.05$, paired $t$ test, $\mathrm{n}=18$ )

In addition to the refractive changes, corneal dystrophy was found in one case, allergic conjunctivitis in two cases, and retinal venous blood retention in one case.

\section{DISCUSSION}

Late onset myopia developed in nine of 12 workers who worked in a pneumatic caisson and most recovered from the induced myopia 6 months after suspension of the work. Ophthalmological disorders in caisson workers have not been reported as far as we know from a Medline search. But some cases of temporary increase of myopia have been reported following hyperbaric oxygen therapy for cerebral ischaemic lesions. Thus, Anderson and Farmer reported a myopic shift in seven patients who received 2 hours of hyperbaric oxygen 40 times. The patients' ages were between 51 and 69 years, and the myopic shift was between -0.50 and $-2.50 \mathrm{D}$ with an average of $-1.61 \mathrm{D}^{6}{ }^{6}$ Lyne also reported a progression of myopia of -0.50 and $-5.50 \mathrm{D}$ in 18 of 26 patients, ages $36-80$ years, who received hyperbaric oxygen therapy. ${ }^{7}$ Palmquist reported that all 25 patients, ages $23-68$, who received oxygen therapy had a myopia shift averaging $-3.0 \mathrm{D}$. The progression of myopia was not found in patients who were treated for less than 100 hours. ${ }^{8}$

Ross et al investigated refraction immediately before and after each exposure to hyperbaric oxygen of 2 hours in $100 \%$

\begin{tabular}{|c|c|c|c|}
\hline Patient No & Age/sex & Change of refraction* $(R / L)$ & Complaints at revisit \\
\hline 3 & $50 / M$ & $+0.5 /+0.25$ & Blurred vision still present \\
\hline 4 & $48 / M$ & $+0.88 /+0.13$ & \\
\hline 5 & $48 / M$ & $+0.88 /+1.12$ & Hyperopia advanced \\
\hline 6 & $45 / M$ & $+2.13 /+1.87$ & Blurred vision still present \\
\hline 7 & $42 / M$ & $-0.5 /-0.5$ & \\
\hline 8 & $38 / M$ & $-0.25 /+0.13$ & Blurred vision still present \\
\hline 9 & $29 / M$ & $-0.13 /+0.13$ & \\
\hline 10 & $25 / M$ & $0 / 0$ & \\
\hline 12 & $22 / M$ & $0 / 0$ & \\
\hline
\end{tabular}


$\mathrm{O}_{2}$ at 2 ATA for 20 exposure sessions. The refraction changed in the direction of myopia in only two of eight patients. They suspected the presence of oxidative damage to the lens protein although oxygen radicals in the blood were not detected. Ross et al mentioned that the axial length, corneal curvature, ciliary body tonus, position of the lens, and refractive power of the lens could be factors that may play a part in the progression of myopia by hyperbaric oxygen. ${ }^{9}$ However, they reported that the axial length and corneal curve did not change in subjects who demonstrated a myopic shift following hyperbaric oxygen exposure. Ross also reported that cycloplegics did not decrease the myopia indicating that these induced refractive errors were not due to accommodative spasms as we found.

Ophthalmological disorders have also been reported in underwater divers. Butler reported that a temporary myopic shift of $-1.5 \mathrm{D}$ in a diver following 84.8 hours using a closed circuit mixed gas underwater breathing apparatus adjusted to provide a constant partial pressure of 1.3 ATA oxygen in a nitrogen-oxygen mixture. ${ }^{10}$

The total exposure times in these earlier studies of induced myopia were 80-850 hours. The total exposure times in our cases were much shorter at 34-64 hours. We calculated that the total exposure time and numbers of sessions until the awareness of blurred vision were 6-40 hours and 4-30 sessions, respectively. Thus, the time of onset of myopia in our cases was shorter than these reported cases, but the time of myopia onset was not clearly stated in these earlier reports.

For the pneumatic caisson workers, the oxygen density in their working environment was $30 \%$ and pressure was $4-5$ ATA so that the oxygen partial pressure was 1.20-1.50 ATA. During hyperbaric oxygen therapy for ischaemic cerebral diseases the oxygen density is $100 \%$ and the pressure is 2 ATA. Thus, the oxygen exposure in caisson workers was less than that for medical treatment.

Palmquist et al suggested that the hyperbaric oxygen therapy induced myopia was associated with nuclear sclerosis of the lens that recovered within 6 months. ${ }^{8}$ This recovery is similar to the recovery in our workers. Palmquist et al suspected that the myopia caused by hyperbaric oxygen exposure was due to lens damage by oxidation and was associated with the formation of large, high density molecules in the lens. The results of experiments performed on guinea pig supports this hypothesis. ${ }^{11-13}$ Palmquist et al explained that induration of the nucleus was usually irreversible but if it was caused by a reaction to a toxin or at an incipient stage it was reversible.

\section{CONCLUSIONS}

A myopic shift was found in nine of 12 workers who worked in a pneumatic caisson. It is possible that the lower levels of oxygen compared to medical hyperbaric treatment could cause the development of myopia in workers in high pressure. Nuclear sclerosis of the lens as seen following hyperbaric oxygen therapy in patients with ischaemic brain insults could be the cause of development of myopia in the caisson workers. Therefore, careful monitoring of workers under these working conditions should be performed for industrial health control.

\section{ACKNOWLEDGEMENTS}

The authors thank Drs Takashi Tokoro and Ritsuko Tanaka for their useful discussion, and Dr Duco Hamasaki for editing this manuscript.

\section{Authors' affiliations}

A Onoo, M Kiyosawa, $\mathbf{H}$ Takase, Department of Ophthalmology and Visual Science, School of Medicine, Tokyo Medical and Dental University, Graduate school, Tokyo, Japan

Y Mano, Division of Health Science, School of Medicine, Tokyo Medical and Dental University, Tokyo, Japan

\section{REFERENCES}

1 Hukumoto S, Iwata T, Ishii $M$, et al. Development of mixed gas system for pneumatic caisson technology in great depth. (Japanese) Kisoko [Basic technology] 1995:23:112-17.

2 Jones GRN. Dysbaric osteonecrosis (caisson disease of bone): are active oxygen species and the endocrine system responsible, and can control of the production of free radicals and their reaction products confer protection? Free Radical Res Commun 1987;4:139-47.

3 Mano Y, Shibayama M. Medical aspects of the environmental sanitation of workplaces in compressed air work in Japan. [Japanese]. Sangyo lgaku [Jpn J Indust Heal] 1987;29:74-81.

4 Butler Jr FK. Diving and hyperbaric ophthalmology. Surv Ophthalmol 1995;39:347-66.

5 Clerk JM. Oxygen toxicity. In: Bennett PB, Elliot DH, eds. The physiology and medicine of diving. 4th ed. Philadelphia: WB Saunders, 1993, 153-7.

6 Anderson Jr B, Farmer Jr JC. Hyperoxic myopia. Trans Am Ophthalmol Soc 1978;76:116-24

7 Lyne AJ. Ocular effects of hyperbaric oxygen. Trans Ophthalmol Soc UK 1978;98:66-8.

8 Palmquist BM, Philipson B, Barr PO. Nuclear cataract and myopia during hyperbaric oxygen therapy. Br J Ophthalmol 1984;68:113-17.

9 Ross ME, Yolton DP, Yolton RL, et al. Myopia associated with hyperbaric oxygen therapy. Optom Vis Sci 1996;73:487-94.

10 Butler Jr FK, White E, Twa M. Hyperoxic myopia in a closed-circuit mixed-gas scuba diver. Undersea and Hyperbaric Med Soc 1999;26:41-5

11 Giblin FJ, Padgaonkar VA, Leverenz VR, et al. Nuclear light scattering, disulfide formation and membrane damage in lenses of older guinea pigs treated with hyperbaric oxygen. Exp Eye Res 1995:60:219-35.

12 Padgaonkar VA, Lin L-R, Leverenz VR, et al. Hyperbaric oxygen in vivo accelerates the loss of cytoskeletal proteins and MIP 26 in guinea pig lens nucleus. Exp Eye Res 1999;68:493-504.

13 Oriowo OM, Bantseev V, Leverenz VR, et al. Myopia inducement by hyperbaric oxygen treatment of guinea pigs. Association for Research in Vision and Ophthalmology (ARVO) 2002:No 193 (abstract). 